\title{
Articles
}

\section{Synthesis and Characterization of Chromium Silicalite}

\author{
José Sílvio T. Mambrim, ${ }^{\dagger}$ Heloise O. Pastore, ${ }^{*},{ }^{\dagger}$ Celso U. Davanzo, ${ }^{\dagger}$ \\ Eduardo J. S. Vichi, ${ }^{*}$, Ossamu Nakamura, ${ }^{\dagger, \S}$ and Helion Vargas ${ }^{\ddagger}$ \\ Instituto de Quimica, Universidade Estadual de Campinas, C.P. 6154, Barão Geraldo, \\ 13081-970 Campinas S.P., Brazil, and Instituto de Fisica Gleb Wataghin, Universidade \\ Estadual de Campinas, C.P. 6165, Barão Geraldo, 13081-970 Campinas S.P., Brazil
}

Received February 20, 1992. Revised Manuscript Received October 12, 1992

\begin{abstract}
Infrared spectroscopy (mid-IR), ${ }^{29} \mathrm{Si}$ and ${ }^{27} \mathrm{Al}$ magic angle spinning nuclear magnetic resonance (MAS-NMR), powder X-ray diffraction (PXRD), electron paramagnetic resonance (EPR), and photoacoustic spectroscopy (PAS), in combination, have produced useful information about a series of crystalline MFI-type chromium silicalite, synthesized in a fluoride medium. Aluminum is an impurity and occupies framework sites, as evaluated by the ${ }^{27} \mathrm{Al}$ MAS-NMR. The mid-IR spectra are very similar to the zeolite ZSM-5 with the addition of a weak band at $\cong 680 \mathrm{~cm}^{-1}$, which we tentatively assign to symmetric stretching of $(\mathrm{Cr}-\mathrm{O}-\mathrm{Si})_{n}$ groups. The samples are crystalline materials and have expanded unit cells, as PXRD measurements pointed out. The as-synthesized sample shows a distribution of $\mathrm{Cr}$ sites, detected by EPR, comprising structure and channel occlusion sites; the nonstructural sites being extensively oxidized to $\mathrm{Cr}$ (VI) species after calcination in the presence of dioxygen. The changes in the photoacoustically measured physical properties, such as nonradiative relaxation time, the thermal diffusivity and optical absorption coefficient of both calcined and noncalcined chromium silicalite samples are also reported.
\end{abstract}

\section{Introduction}

Zeolitic materials (zeolite-based molecular sieves) containing elements other than aluminum or silicon in the conventional lattice have received increasing attention in recent years, ${ }^{1}$ owing to the possibilities offered by the presence of a heteroelement in the structure. From the catalytic point of view, incorporation of elements other than aluminum in the structure is important since the metallosilicate might have its properties fine-tuned for the selective production of desired compounds. ${ }^{2}$ Among the characteristics that determine the selectivity, the structure and dimensions of the system of pores and channels ${ }^{3}$ (shape selectivity), the Bronsted acidity of sites ${ }^{4}$ (quimioselectivity), and the generalized effects arising from differences in the electronegativities of the elements in the structure ${ }^{5}$ are the most important. It is well-known that the ZSM-5 structure, with three-dimensional pore network is outstandingly effective in converting methanol

\footnotetext{
†nstituto de Química.

t Instituto de Física Gleb Wataghin

$\$$ On leave of absence from Instituto de Física, Universidade Federal da Bahia, 40210 Salvador BA, Brasil.

(1) (a) Gabelica, Z.; Guth, J. L. Angew. Chem., Int. Ed. Engl. 1989, 86, 81. (b) Kofke, T. J. G.; Gork, R. J.; Kokotailo, G. T. J. Catal. 1989 116, 252. (c) Chu, C. T. W.; Chang, C. D. J. Phys. Chem. 1985, 89, 1569 (d) Wilson, S. T.; Lok, B. M.; Messina, C. A.; Cannan, T. R.; Flanigen, E. M. ACS Symp. Ser. 1983, 218, 79. (e) Meagher, A.; Nair, V.; Szostak, R. Zeolites 1988, 8, 3 .

(2) (a) Kaeding, W. W.: Butter, S. A. J. Catal, 1980, 61, 158. (b) McIntosh R. J.: Seddon, D. Appl. Catal. 1983, 6, 307. (c) Védrine, J. C. Auroux, A.; Dejaifve, P.; Ducarme, V.; Hoser, H.; Zhou, S. J. Catal. 1982, 73,147 .

(3) Guth, J. L.; Caullet, P. J. Chim. Phys. 1986, 86, 155

(4) Ward, J. W. ACS Monograph Ser. 1976, 171, 118.

(5) Mortier, W. J.; Schoonheydt, R. A. Prog. Solid State Chem. 1985 16,1 .
}

$0897-4756 / 93 / 2805-0166 \$ 04.00 / 0$ to high-octane gasoline. ${ }^{6}$ The final mixture is rich in paraffins and aromatics but very poor in olefins. ${ }^{7}$ Incorporation of metal atoms other than aluminum can improve dramatically the selectivity of the molecular sieve toward convertion of methanol to olefins, ${ }^{8-11}$ this selectivity increasing as the Bronsted sites become less acidic. ${ }^{8}$ However, the difficulties in determining the amount of metal incorporated, the thermal stability of the metal in the structure and the difficulty in removing the occluded metallic compounds limit the possibilities of application of these materials in an industrial level.

In this paper, the synthesis, in neutral fluoride medium, of chromium silicalites with MFI structure is described. The products were characterized by chemical analysis, powder X-ray diffraction, infrared spectroscopy, and magic angle spinning nuclear magnetic resonance. The distri-

(6) (a) Chang, C. D.; Lang, W. H.; Smith, R. L. J. Catal. 1979, 56, 169. (b) Chang, C. D.; Silvestri, A. J. J. Catal. 1977, 47, 249. (c) Derouane, E. G.; Nagy, J. B.; Dejaifve, P.; van Hooff, J. H. C.; Spekman, B. P.; Védrine, J. C.; Naccache, C. J. Catal. 1978, 53, 40. (d) Anderson, J. R.; Foger, K.; Mole, R.; Rajadhyaksha, R. A.; Saunders, J. V. J. Catal. 1979, 58, 114. (e) Bragin, O. V.; Nefedov, B. K.: Vasina, T. V.: Alekseeva, T. Lutovinova, V. N.; Minachev, K. M. Izv. Akad. Nauk SSSR, Ser. Khim. 1979, 11, 2639. (f) Dejaifve, P.; Védrine, J. C.; Bolis, V.; Derouane, E. G. J. Catal. 1980, 63, 331. (g) Chang, C. D.; Chu, C. T. W. J. Catal. 1982, 74, 203. (h) Chang, C. D.; Lang, W. H.; Silvestri, A.J.U.S. Patent 4,052,479, 1977.

(7) Morgan, C. R.; Warner, J. P.; Yurchak, S. Ind. Eng. Chem., Prod. Res. Dev. 1981, 20, 185.

(8) Inui, T.; Matsuda, H.; Yamase, O.; Nagata, H.; Fukuda, K.; Ukawa, T.; Miyamoto, A. J. Catal. 1986, 98, 491.

(9) Ione, K. G.; Vostrikova, L. A.; Petrova, A. V.; Mastikhin, V. M. Stud. Surf. Sci. Catal. 1984, 18, 151.

(10) Ione, K. G.; Vostrikova, L. A.; Mastikhin, V. M. J. Mol. Catal. $1985,31,355$.

(11) Borade, R. B.; Halgeri, A. B.; Rao, T. S. R. P. Stud. Surf. Sci. Catal. 1986, 28, 851 .

(C) 1993 American Chemical Society 
Table I. Elemental Analysis (wt \%) of As-Synthesized (AS) and Ionic Exchanged (IE) Samples

\begin{tabular}{|c|c|c|c|c|c|c|c|}
\hline sample ${ }^{a}$ & color & $\mathrm{SiO}_{2}$ & $\mathrm{Al}_{2} \mathrm{O}_{3}$ & $\mathrm{Cr}_{2} \mathrm{O}_{3}$ & $\mathrm{Fe}_{2} \mathrm{O}_{3}$ & $\mathrm{Na}_{2} \mathrm{O}$ & $\mathrm{SiO}_{2} / \mathrm{Cr}_{2} \mathrm{O}_{3}$ \\
\hline $\begin{array}{l}\text { Cr-100(AS) } \\
\text { Cr-50(AS) }\end{array}$ & $\begin{array}{l}\text { white } \\
\text { light } \\
\text { green }\end{array}$ & $\begin{array}{l}81.60 \\
82.40\end{array}$ & $\begin{array}{l}1.00 \\
0.64\end{array}$ & $\begin{array}{l}0.90 \\
1.70\end{array}$ & $\begin{array}{r}0.02 \\
<0.01\end{array}$ & $\begin{array}{l}2.41 \\
2.28\end{array}$ & $\begin{array}{l}743 \\
492\end{array}$ \\
\hline $\begin{array}{l}\text { Cr-30(AS) } \\
\text { Cr-100(IE) } \\
\text { Cr-30(IE) }\end{array}$ & $\begin{array}{l}\text { green } \\
\text { white } \\
\text { very light }\end{array}$ & $\begin{array}{l}81.30 \\
84.5\end{array}$ & $\begin{array}{l}0.93 \\
0.08\end{array}$ & $\begin{array}{l}1.25 \\
0.01\end{array}$ & $\begin{array}{l}0.04 \\
0.04\end{array}$ & $\begin{array}{l}2.19 \\
0.04\end{array}$ & $\begin{array}{l}165 \\
20000\end{array}$ \\
\hline & green & 82.4 & 0.19 & 0.79 & $<0.01$ & 0.07 & 264 \\
\hline
\end{tabular}

${ }^{a} \mathrm{Cr}-100$ is a chromium silicalite sample whose $\mathrm{SiO}_{2} / \mathrm{Cr}_{2} \mathrm{O}_{3}$ ratio in the reactional mixture is 100 . The same for $\mathrm{Cr}-50$ and $\mathrm{Cr}-30 .{ }^{b} \mathrm{AS}=$ as-synthesized. ${ }^{c}$ IE $=$ ion exchanged.

bution and nature of each $\mathrm{Cr}$ (III) site in the material, the metal atom redox characteristics as well as its optical, thermal, and magnetic properties were examined using electron paramagnetic resonance and photoacoustic spectroscopy. Preliminary accounts of this work were published previously. ${ }^{12,13}$

\section{Experimental Section}

Synthesis. A mixture of sodium silicate (Riedel de-Haen: $63 \% \mathrm{SiO}_{2}, 18 \% \mathrm{Na}_{2} \mathrm{O}$, and $18 \%$ water), ammonium fluoride, chromium nitrate 9-hydrate, and water, in that order, was prepared in the ratio $0.1(9.5372 \mathrm{~g}): 0.05(1.8519 \mathrm{~g}): 0.002(0.6283$ g): $6.0(108.09 \mathrm{~g})$, for the synthesis of a sample with $\mathrm{SiO}_{2} / \mathrm{Cr}_{2} \mathrm{O}_{3}$ ratio of 100 in the initial mixture. The $\mathrm{pH}$ was adjusted to 6.57.0 with $48 \mathrm{vol} \% \mathrm{HF}$. After $2 \mathrm{~h}$ of stirring, tetrapropylammonium bromide was added in a $40-\mathrm{mL}$ aqueous solution. The suspension was left to age for $24 \mathrm{~h}$, at 348-353 K, under ambient pressure. The hydrothermal treatment was performed at $443-448 \mathrm{~K}$ for 15 days. The crystallized chromium silicalite was then filtered, extensively washed with distilled water until neutral $\mathrm{pH}$, and air-dried. The samples were kept in a desiccator over saturated $\mathrm{CaCl}_{2}$ solution before the measurements. For ion exchanges the following procedure was used: $1 \mathrm{~g}$ of the metallosilicalite was slurried in $12.5 \mathrm{~mL}$ of a $0.1 \mathrm{M} \mathrm{HCl}$ aqueous solution. After 24 $\mathrm{h}$, the samples were washed with distilled water until neutral $\mathrm{pH}$ and no $\mathrm{Cl}^{-}$could be detected in the washings. The material was air-dried. Samples were commonly calcined in a open furnace, for $24 \mathrm{~h}$ at $693 \mathrm{~K}$, unless otherwise specified.

Elemental Analysis. The silicalites were analyzed for their $\mathrm{Si}, \mathrm{Al}, \mathrm{Cr}, \mathrm{Fe}$, and $\mathrm{Na}$ content by atomic absorption after the samples had been dissolved in $\mathrm{HF}$ or melt with sodium carbonate. The results obtained by both methods agree within $0.01 \%$ error and are presented in Table I.

Scanning Electron Microscopy (SEM). Samples were dispersed over ordinary double-sided tape, glued to the microscope sample holder, and coated with gold. The accelerating voltage was $25 \mathrm{kV}$, and the image was obtained from secondary electrons. The scanning microscope was a JEOL Model JSMT300.

Magic Angle Spinning Nuclear Magnetic Resonance (MAS-NMR). These were collected for ${ }^{29} \mathrm{Si}$ and ${ }^{27} \mathrm{Al}$ in a Brucker AC300/P with Kel-F rotors, using TMS and an acidic $\left[\mathrm{Al}\left(\mathrm{H}_{2} \mathrm{O}\right)_{6}\right]^{3+}$ solution as references, respectively. The frequencies were 59.628 (Si) and $78.206 \mathrm{MHz}(\mathrm{Al})$, and $1100(\mathrm{Si})$ and 40000 (Al) scans were accumulated. The spinning rate was typically $4500 \mathrm{~Hz}$.

Powder X-ray Diffraction (PXRD). The chromium silicalites were analyzed with a Shimadzu diffractometer, Model XD3A ( $30 \mathrm{kV}, 20 \mathrm{~mA}, 2 \theta 2^{\circ} \mathrm{min}^{-1}$ ) using $\mathrm{Cu} \mathrm{K} \alpha$ radiation. The samples are highly crystalline phase-pure ZSM-5 molecular sieves. They present orthorhombic symmetry when as-synthesized and an orthorhombic-to-monoclinic phase transition upon calcination at $693 \mathrm{~K}$. This phase transition is expected for these $\mathrm{SiO}_{2} / \mathrm{T}_{2} \mathrm{O}_{3}$ ratios, ${ }^{12}$ where $T$ is the general nomenclature for atoms in the

(12) Pastore, H. O.; Stein, E.; Davanzo, C. U.; Vichi, E. J. S.; Nakamura, O. Baesso, M.; Silva, E. C.; Vargas, H. J. Chem. Soc., Chem. Commun. 1990,772 .

(13) (a) Mambrim, J. S. T.; Vichi, E. J. S.; Pastore, H. O.; Davanzo, C. U.; Vargas, H.; Silva, E. C.; Nakamura, O. J. Chem. Soc., Chem. Commun. 1991, 141. (b) Nakamura, O.; Mambrim, J. S. T.; Pastore, H. O.; Vichi, E. J. S.; Gandra, F. G.; Silva, E. C.; Vargas, H.; Pelz, J. J. Chem. Soc., Faraday Trans. 1992, 88, 2071.
Table II. Optical Densities Ratios for the Bands at 550 and $450 \mathrm{~cm}^{-1}$, for As-Synthesized (AS) and Calcined (C) Samples

\begin{tabular}{|c|c|c|c|c|c|c|}
\hline \multirow[b]{2}{*}{ sample } & \multicolumn{2}{|c|}{$A^{550} / A^{450}$} & \multicolumn{2}{|c|}{$\nu\left[(\mathrm{Si}-\mathrm{O}-\mathrm{Si})_{n}\right], \mathrm{cm}^{-1}$} & \multicolumn{2}{|c|}{$\nu\left[(\mathrm{Si}-\mathrm{O}-\mathrm{Cr})_{n}\right], \mathrm{cm}^{-1}$} \\
\hline & AS & $\mathrm{C}$ & AS & $\mathrm{C}$ & AS & $\mathrm{C}$ \\
\hline $\begin{array}{l}\text { Cr-100 } \\
\text { Cr-50 } \\
\text { Cr-30 }\end{array}$ & $\begin{array}{l}0.75 \\
0.79 \\
0.88\end{array}$ & $\begin{array}{l}0.81 \\
0.79 \\
0.82\end{array}$ & $\begin{array}{l}793 \\
788 \\
795\end{array}$ & $\begin{array}{l}796 \\
799 \\
795\end{array}$ & $\begin{array}{l}690 \\
695 \\
696\end{array}$ & $\begin{array}{l}689 \\
691 \\
680\end{array}$ \\
\hline
\end{tabular}

framework of zeolites or zeolitic metallosilicalites. For the determination of unit cell volumes, the diffractogram was scanned at $2 \theta 1^{\circ} \mathrm{min}^{-1}$. The (012), (031), (022), (-103), (033), (501), (503), $(1000)$, and $(400)$ diffractions were used to calculate the unit cell volumes for monoclinic samples, while $(020),(102),(501)$, (151), (303), (133), (432), (352), (1000), and (0 100) were used for orthorhombic ones.

Infrared Spectroscopy (MID-IR). Potassium bromide pellets $(0.5 \mathrm{wt} \%)$ were measured in a Jasco IR 700 spectrophotometer, the ratio of 550 to $450 \mathrm{~cm}^{-1}$ optical densities for assynthesized (AS) and calcined (C) samples are listed in Table II.

Electron Paramagnetic Resonance (EPR). Spectra were obtained using a Varian E-12 spectrometer operating at $9.5 \mathrm{GHz}$ (X-band). The $g$ values of the samples were obtained with reference to a standard mark: diphenylpycrilhydrazine (DPPH), $g$ value 2.0036 . The spectra were recorded on samples at the liquid nitrogen $(77 \mathrm{~K})$ and at room temperature $(300 \mathrm{~K})$.

Photoacoustic Spectroscopy (PAS). The optical absorption measurements were carried out at room temperature in the wavelength range $300-700 \mathrm{~nm}$ using an EDT Model OAS-400 photoacoustic spectrometer. The thermal properties, the nonradiative relaxation time and the optical absorption coefficients were measured by using instrumentation and techniques described previously. ${ }^{16-16}$

Computational Fittings. The ESR experimental data are fitted to theoretical expressions using an IBM 3090 computer. The expressions used are composed of the superposition of symmetrical line shapes with powder pattern line shapes. The routines used for the fittings are those of Bevington. ${ }^{17}$

\section{Results and Discussion}

Synthesis. Among the several factors involved in the preparation of metallosilicalites, the form in which the trivalent cation is introduced in the synthesis mixture seems to be one of the most critical. In basic medium, where most of the zeolitic aluminosilicates are prepared, ${ }^{18,19}$ the incorporation of other metals is made difficult owing to formation of less-soluble hydroxo compounds, as in the

(14) Iacovacci, M.; Silva, E. C.; Vargas, H.; Pinheiro, E. A.; Galembeck, F.; Miranda, L. C. M. J. Appl. Phys. 1989, 65, 5150.

(15) Abrita, T.; Cella, N.; Vargas, H. Chem. Phys. Lett. 1989, 161, 12.

(16) Nakamura, O.; Mansanares, A. M.; Vargas, H.; Pastore, H. O. Vichi, E. J.S.; Leite, N.F.;Miranda, L. C. M. Paper P IV/21, Photoacoustic and Photothermal Phenomena, 7th International Topical Meeting; Doorwerth: The Netherlands, 1991; p 475.

(17) Bevington, P. R. Data Reduction and Error Analysis for the Physical Sciences; McGraw Hill: New York, 1969.

(18) Breck, D. W. Zeolite Molecular Sieves; Wiley-Interscience: New York, 1974.

(19) Szostak, R. Molecular Sieves, Principles of Synthesis and Identification; Van Nostrand: New York, 1989. 
case of iron, or those that do not polycondensate easily as in the case of germanium. ${ }^{20}$ In fluoride medium, the $\mathrm{pH}$ can be lowered, and less supersaturated reaction mixtures are formed compared to in an alkaline medium, ${ }^{21}$ leading to less metastable phases which produce more well-formed crystals. The key point is the formation of soluble metal fluoro complexes which are labile enough to provide a more well-controlled nucleation of the zeolite precursors. For different metal incorporation a compromise between $\mathrm{pH}$ and $\mathrm{F}^{-}$concentration has to be reached, to optimize the synthesis, due to differences in the stability-lability of the different fluorocomplexes. In the chromium silicalite synthesis described in this paper, higher ageing times and higher temperatures are required compared to the used for other metallosilicalites. ${ }^{22}$ Several $\mathrm{pH}$ and $\mathrm{F}^{-}$concentrations were checked before using those described in the synthetic procedure, which allowed some but not varied incorporation. The selection of the template used to direct the construction of the skeletal structure is another critical point since a variety of phases can be produced depending on the nature of the template. The tetrapropylammonium bromide salt used in the synthesis of the chromium silicalite described here seems to be the more selective template to direct the construction of MFI-type structures. ${ }^{21}$

Chemical Composition and Crystal Morphology. Apart from the presence of chromium in the samples, the results of the elemental analysis displayed in Table I show that $\mathrm{Al}_{2} \mathrm{O}_{3}$ is incorporated in the chromium silicalite samples as an impurity, probably coming from the $\mathrm{Si}$ source. The location of Al(III) ions in the tetrahedral framework sites is indicated by the ${ }^{27} \mathrm{Al}$ MAS-NMR spectra which show a single and characteristic peak at $52.3 \mathrm{ppm} .{ }^{23}$ The presence of $\mathrm{Si}(\mathrm{OAl})$ groups in high-silica ZSM-5 structures is confirmed by a peak at $-112 \mathrm{ppm}$ in the ${ }^{29} \mathrm{Si}$ MAS-NMR spectra. ${ }^{23}$ This peak has shoulders in either higher or lower fields depending on the sample measured, resembling the positions where a high-resolution spectrum would show resolved peaks. ${ }^{23}$ However, due to the high $\mathrm{SiO}_{2} / \mathrm{Al}_{2} \mathrm{O}_{3}$ ratio, none of the shoulders at lower field is in the region expected for $\mathrm{Si}(1 \mathrm{Al}) .{ }^{23}$ The crystals are rather elongated with sizes varying from 15 to $55 \mu \mathrm{m}$ on the longer dimension by $14-\mu \mathrm{m}$ width (Figure 1 ). In Figure $1 \mathrm{~b}$ it is possible to observe noncrystallized material adhering to the crystal surface and some extent of intergrowth. Treatment with aqueous $\mathrm{HCl}$ was not efficient in dissolving this extraneous material. All the samples are homogeneous, i.e., the crystals present the same morphology from one synthesis batch to another and approximately the same dimensions within the same batch.

Structural Characterization. Unit Cell Expansion. The co-incorporation of aluminum and chromium in the silicalite framework is expected to cause a unit cell expansion to an extent proportional to the quantity of these $\mathrm{T}$ atoms per silicalite unit cell. Assuming that the $\mathrm{T}-\mathrm{O}-\mathrm{T}$ bond angles do not change with the incorporation of $\mathrm{T}$ atoms different from $\mathrm{Si}$ in the framework ${ }^{24}$ the unit 1.

(20) Guth, J. L.; Kessler, H.; Wey, R. Stud. Surf. Sci. Catal. 1987, 33,

(21) Guth, J. L.; Kessler, H.; Lamblin, J. M.; Patarin, J.; Siene, A.; Chezeau, J. M.; Wey, R. ACS Symp. Ser. 1989, 398, 176.

(22) For rates of ligand exchange in $\mathrm{Cr}(\mathrm{III})$ compounds see: Mechanisms of Inorganic and Organometallic Reactions; Twigg, M. V., Ed.; Plenum Press: London, 1990; Vol. 7, p 125, and references therein.

(23) Engelhardt, G.; Michel, D. High-Resolution Solid State NMR of Silicates and Zeolites; John Wiley and Sons: New York, 1987.

(24) Bellussi, G.; Millini, R.; Carati, A.; Maddinelli, G.; Gervasini, A. Zeolites 1990, 10, 642 .
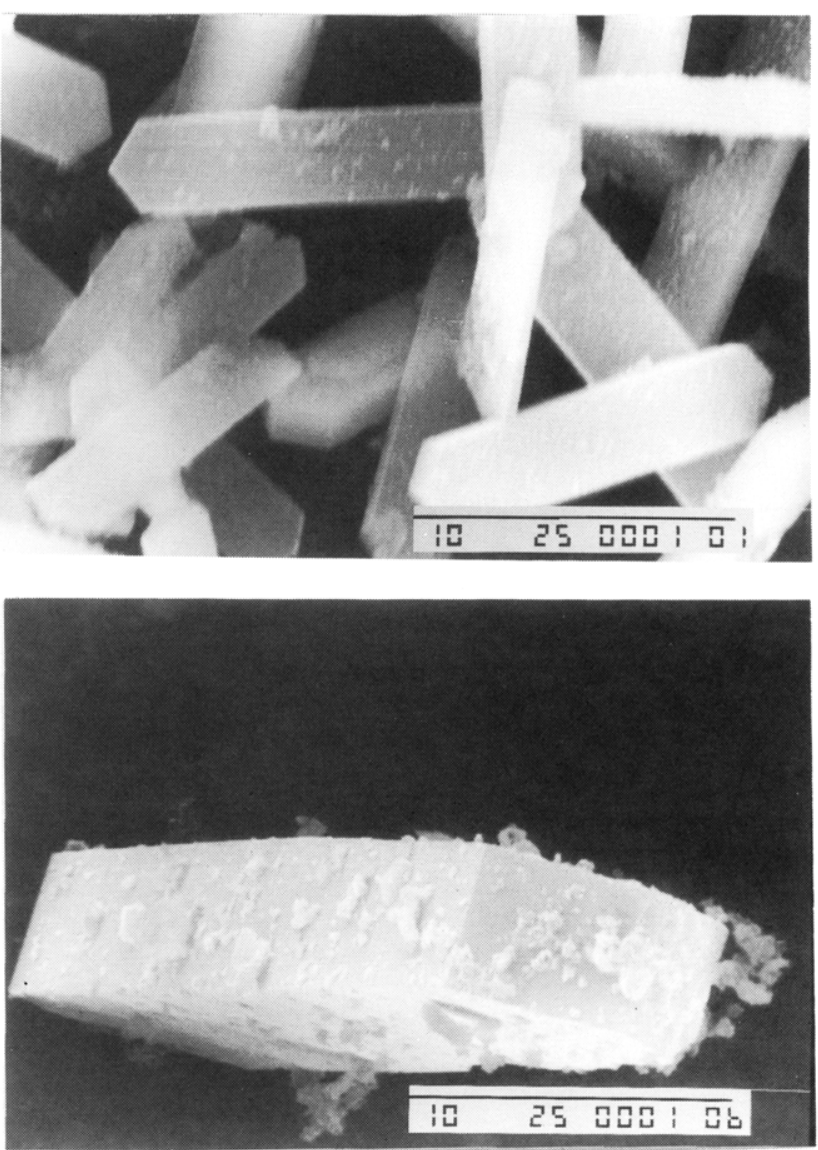

Figure 1. SEM micrographs of (a, top) $\mathrm{Cr}-30$ and (b, bottom) Cr-100.

Table III. Unit Cell Volumes Calculated from XRD for Calcined, $V_{\mathrm{xr}}(\mathrm{C})$, and As-Synthesized, $V_{\mathrm{xr}}(\mathrm{AS})$, Samples and Calculated from the Aluminum Concentration, $V_{\text {calc }}$

\begin{tabular}{lccc}
\hline sample & $V_{\text {calc }} / 10^{3} \AA^{3}$ & $V_{\text {xr }}(\mathrm{AS}) / 10^{3} \AA^{3}$ & $V_{\text {xr }}(\mathrm{C}) / 10^{3} \AA^{3}$ \\
\hline $\mathrm{Cr}-30$ & 5.31 & $5.44 \pm 0.08$ & $5.43 \pm 0.03$ \\
$\mathrm{Cr}-50$ & 5.31 & $5.51 \pm 0.08$ & $5.36 \pm 0.03$ \\
$\mathrm{Cr}-100$ & 5.31 & $5.4 \pm 0.1$ & $5.38 \pm 0.09$
\end{tabular}

cell expansion can be calculated using eq 1 , where $V_{\mathrm{Si}}$ is

$$
V_{x}(\mathrm{Al})=V_{\mathrm{Si}}-x V_{\mathrm{Si}}\left[1-\left(d_{\mathrm{Al}-0} / d_{\mathrm{Si}-0}\right)^{3}\right]
$$

the unit cell volume when $\mathrm{T}=\mathrm{Si}$ only $\left(5298 \AA^{3}\right.$ according to ref 25$) ; V_{x}(\mathrm{Al})$ is the unit cell volume of the same lattice where a molar fraction, $x$, of $\mathrm{Si}$ atoms has been replaced by $\mathrm{Al}$ atoms; and $d_{\mathrm{Al}-\mathrm{O}}$ and $d_{\mathrm{Si}-\mathrm{O}}$ are the related bond distances $\left(1.71^{26}\right.$ and $1.61 \AA,{ }^{27}$ respectively). Table III lists the expected unit cell expansion due to $\mathrm{Al}$ incorporation only, along with the PXRD-measured cell volume for as-synthesized, $V_{\mathrm{xr}}(\mathrm{AS})$, and calcined, $V_{\mathrm{xr}}(\mathrm{C})$, chromium silicalites. It is clear that for samples $\mathrm{Cr}-30$ and $\mathrm{Cr}-50, V_{\mathrm{xr}}(\mathrm{AS})$ is higher, within deviation, than $V_{\mathrm{x}}(\mathrm{Al})$. For sample Cr-100, however, we cannot be sure about chromium(III) incorporation since the expansion might be due solely to aluminum substitution. The same applies to calcined samples: $\mathrm{Cr}-30$ and $\mathrm{Cr}-50$ still have a unit cell volume higher than $V_{\mathrm{x}}(\mathrm{Al})$. The unit cell volume variations are within the range $50-200 \AA^{3}$ in excess of the volume

(25) Bell, R. G.; Jackson, R. A.; Catlow, R. A. J. Chem. Soc., Chem. Commun. 1990, 782 .

(26) Cichocki, A.; Kaczmarska, J. P.; Michalik, M.; Bus, M. Zeolites 1990, 10, 577 .

(27) Cichocki, A.; Datka, J.; Olech, A.; Piwowarska, Z.; Michalik, M. J. Chem. Soc., Faraday Trans. 1990, 86, 753. 


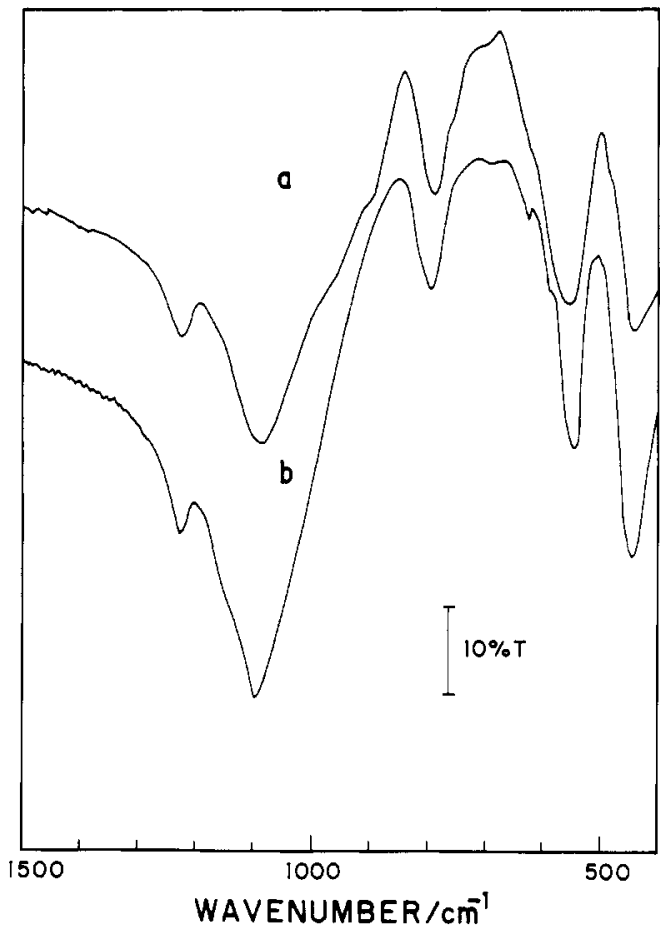

Figure 2. Mid-IR spectra of (a) $\mathrm{Cr}-100$ as-synthesized and (b) Cr- 100 calcined for $24 \mathrm{~h}$ at $693 \mathrm{~K}$.

calculated taking into account the aluminum incorporation only. This is in agreement with values for the unit cell expansion caused by the incorporation of boron, ${ }^{28}$ gallium, ${ }^{28}$, aluminum, ${ }^{28,29}$ germanium, ${ }^{30}$ and titanium ${ }^{31,32}$ into the silicalite framework, reported in the literature. Since the length of $\mathrm{Cr}-\mathrm{O}$ bond in a perfect or distorted tetrahedral symmetry is not yet known, the values for unit cell expansion obtained here for the chromium silicalites cannot be discussed further, except that they provide some evidence for the incorporation of some of the $\mathrm{Cr}$ (III) in the silicalite framework.

Crystallinity of the Material and Skeletal Vibrations. IR spectroscopy has been widely used as a technique for the identification of zeolites. ${ }^{33}$ Two types of characteristic absorptions are observed in the IR spectra of zeolites; those related to the internal vibrations of the $\mathrm{TO}_{4}$ tetrahedron, and those related to the vibrations of the skeleton formed by the tridimensional bonding of those tetrahedra. In zeolites with pentasil structure the bands at $450 \mathrm{~cm}^{-1}$, assigned to the internal vibrations of the tetrahedra $\mathrm{TO}_{4}$ $\left(\mathrm{T}=\mathrm{Si}, \mathrm{Al}\right.$ ) and the band at $550 \mathrm{~cm}^{-1}$, assigned to the vibrations of the secondary building units $\mathrm{C}_{5}-\mathrm{T}_{1}$ can be used to evaluate the degree of crystallinity of these materials. After Vedrine et al., ${ }^{34}$ a ratio $A^{550} / A^{450} \geq 0.72$ has been widely used as a criterium for high crystallinity of ZSM-5 type zeolites. The $A^{550} / A^{450}$ values obtained for the chromium silicalite prepared in this work are show in Table II and provide further evidence for the high

(28) Rurem, X.; Wenqin, P. Stud. Surf. Sci. Catal. 1985, 24, 27.

(29) Olson, D. H.; Kokotailo, G. T.; Lawton, S. L.; Meier, W. M. J. Phys. Chem. 1981, 85, 2238.

(30) Gabelica, Z.; Guth, J. L. Stud. Surf. Sci. Catal. 1989, 49A, 421.

(31) Chiu, S.; Pang, W.; Yao, S. Stud. Surf. Sci. Catal. 1989, 49A, 133

(32) Perego, G.; Bellussi, G.; Corno, C.; Taramosso, M.; Buonomo, F Esposito, A. Stud. Surf. Sci. Catal. 1986, 28, 129.

(33) Flanigen, E. M.; Khatami, H.; Szymanski, H. A. Molecular Sieves Zeolites I; Adv. Chem. Ser. 101; Flanigen, E. M., Sand, L. B., Eds.; American Chemical Society: Washington, DC, 1971, p 201.

(34) Coudurier, G.; Naccache, C.; Védrine, J. C. J. Chem. Soc., Chem. Commun. 1982, 1413 .

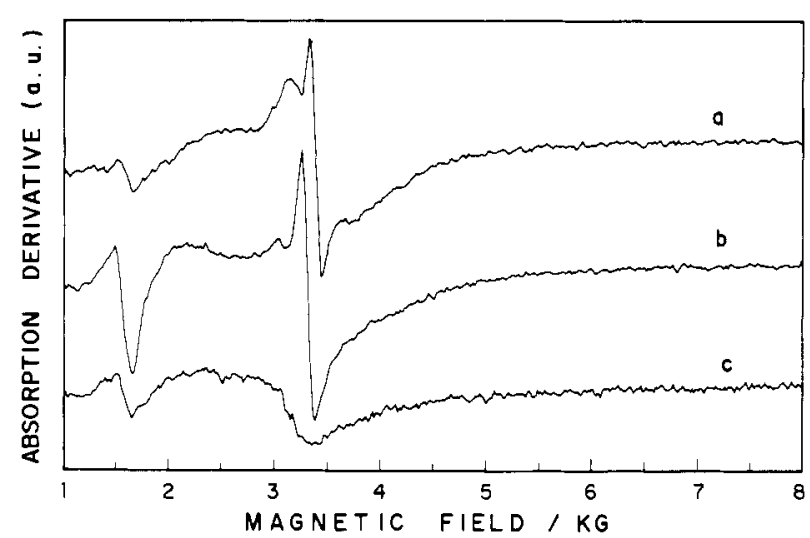

Figure 3. EPR spectra of a silicalite sample (a) as-synthesized at room temperature, (b) as-synthesized at liquid nitrogen temperature, and (c) calcined for $24 \mathrm{~h}$ at $693 \mathrm{~K}$.

crystallinity of these materials. The mid-IR spectra of Cr-100 samples, shown in Figure 2, may also provide some evidence for the incorporation of a small amount of $\mathrm{Cr}$ (III) in the silicalite framework. The difference in atomic mass of $\mathrm{Si}(\mathrm{IV})$ and $\mathrm{Cr}(\mathrm{III})$ in the skeleton is enough to pinpoint contributions of $(\mathrm{Si}-\mathrm{O}-\mathrm{Cr})$ vibrations to the IR spectra. The bands around $795 \mathrm{~cm}^{-1}$ in Figure 2 are assigned to the symmetric stretching of the ( $\mathrm{Si}-\mathrm{O}-\mathrm{Si})_{n}$ group; the very weak bands around $690 \mathrm{~cm}^{-1}$ are tentatively assigned to the symmetric stretching of the ( $\mathrm{Si}-\mathrm{O}-\mathrm{Cr})$ group, due to the incorporation of a very small amount of $\mathrm{Cr}$ (III) in the framework. These bands are still present in the spectrum after calcination of the material. The frequencies obtained for the samples studied are in Table II. The broadening in the lower wavenumber side of the $(\mathrm{Si}-\mathrm{O}-\mathrm{Si})_{n}$ of the as-synthesized sample which could be due to asymmetric vibration of the $(\mathrm{Si}-\mathrm{O}-\mathrm{Cr})_{n}$ groups $^{35}$ disappear after calcination. Therefore it may be assigned to $\mathrm{Si}-\mathrm{F}$ and $\mathrm{Si}-\mathrm{OH}$, which are expected to show bands in this region. ${ }^{36}$ These may condense and be annealed by calcination. ${ }^{37}$

Distribution of the Cr(III) Species in Chromium Silicalite. The EPR study of the materials shows that the $\mathrm{Cr}$ (III) ions are distributed in the solid occupying at least three different sites. The assignment of the sites was made by comparing the EPR spectra of pure silicalite and chromium silicalite samples. Figure 3 shows the effect of temperature and calcination on the spectrum of a pure silicalite sample prepared by the same procedure used for the chromium silicalite, without the $\mathrm{Cr}$ (III) source. It contains, therefore, nearly the same amount of $\mathrm{Fe}$ (III) and Al(III) found in the chromium silicalite. The assynthesized sample spectra at 300 and $77 \mathrm{~K}$ show a broad peak centered at $g \cong 2.0$, superimposed with a sharp signal at $g=1.97$ (Figures $3 \mathrm{a}, \mathrm{b}$ ). Calcination at $843 \mathrm{~K}$ causes a drastic decrease in the intensity of these signals (Figure $3 \mathrm{c}$ ), suggesting that the signal at $g=1.97$ is probably due to radicals formed during the synthesis or sample workup. The sharp and weak peak at $g=4.27$, due to Fe(III) impurities, is not affected by calcination. The spectra of a Cr-30 chromium silicalite sample, at 300 and $77 \mathrm{~K}$, shown in Figure 4, which include resonances at high $g$ values, are interpreted after performing a deconvolution considering the contributions of the symmetrical line centered at $g \cong$ 2.0 , the background silicalite spectra, and two powder

(35) Szostak, R.; Thomas, T. L. J. Chem. Soc., Chem. Commun. 1986, 113; J. Catal. 1986, 101, 549.

(36) Wood, D. L.; Rabinovitch, E. M. Appl. Spectrosc. 1989, 43, 263

(37) Delmotte, L.; Soulard, M.; Guth, F.; Seive, A.; Lopez, A.; Guth, J. L. Zeolites $1990,10,778$. 


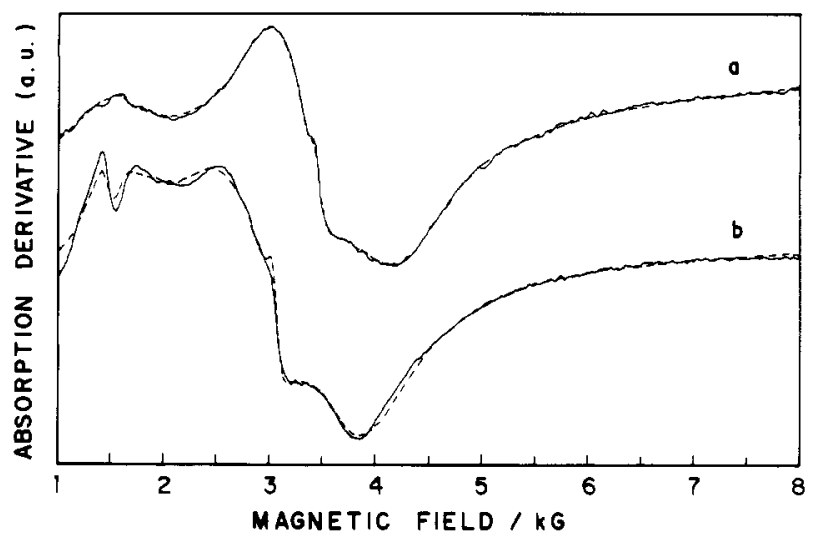

Figure 4. EPR spectra of crystalline zeolitic chromium silicalite, Cr-30 as-synthesized (a) at room temperature and (b) at liquid nitrogen temperature. Dashed lines correspond to the best fit to the experimental curve.

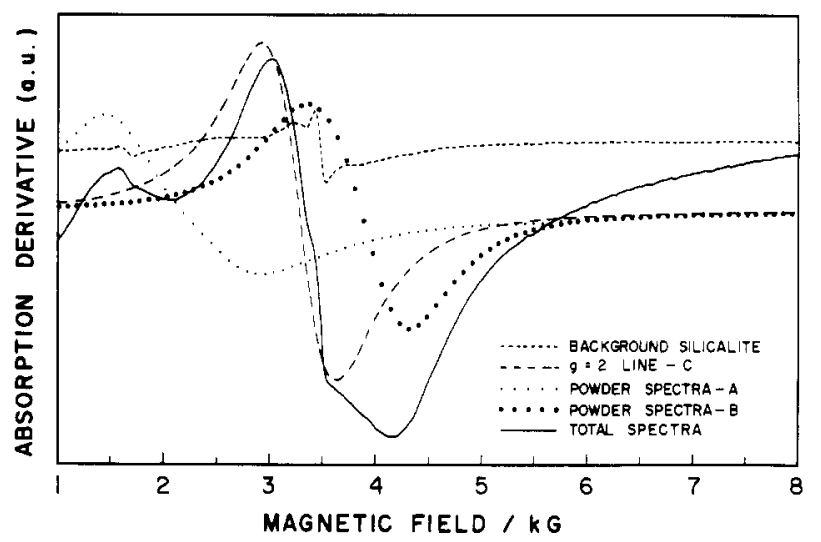

Figure 5. Deconvolution of the experimental EPR curve of crystalline zeolitic chromium silicalite at room temperature. Inset: the main contributions used for the fitting process.

Table IV. $g$ Values for Cr-30, Obtained from the Fitting of the Experimental Spectra

\begin{tabular}{llcl}
\hline & \multicolumn{2}{c}{ temp/K } & \\
\cline { 2 - 4 } & 300 & $\mathbf{7 7}$ & site \\
\hline $\boldsymbol{g}_{x}{ }^{a}$ & 4.49 & 4.06 & \\
$\boldsymbol{g}_{y}$ & 2.71 & 2.19 & \\
$\boldsymbol{g}_{z}$ & 1.66 & 2.03 & $\mathrm{~A}$ \\
$\Delta H / \mathrm{kG}^{b}$ & 0.60 & 0.43 & \\
$\boldsymbol{A}^{c}$ & 1.50 & 1.04 & \\
$\boldsymbol{g}_{x}$ & 2.00 & 2.61 & \\
$\boldsymbol{g}_{y}$ & 1.67 & 1.75 & $\mathrm{~B}$ \\
$\boldsymbol{g}_{z}$ & 1.66 & 1.69 & \\
$\Delta H / \mathrm{kG}^{b}$ & 0.66 & 0.56 & \\
$A^{c}$ & 5.23 & 3.66 & $\mathrm{C}$ \\
$\boldsymbol{g}$ & 2.08 & 1.88 & \\
$\Delta H / \mathrm{kG}^{b}$ & 0.61 & 1.19 & \\
$\boldsymbol{A}^{c}$ & 0.14 & 0.35 &
\end{tabular}

${ }^{a} g$ value within $\pm 0.3 .{ }^{b} \Delta H$ is the line width within $\pm 50 \mathrm{G} .{ }^{c} A$ is the relative amplitude.

pattern line-shaped spectra, as shown in Figure 5. The dashed lines in Figure 4 correspond to the best fit to the experimental data. For the assignment of the different $\mathrm{Cr}$ (III) sites, it was assumed that the powder line shaped resonances are due to two sites, $A$ and $B$, which suffer the action of crystalline fields with different cubic distortions. The symmetrical line $\mathrm{C}$ centered at $\mathrm{g} \cong 2.0$ is assigned ${ }^{38}$ to the ion-exchange cations $\left[\mathrm{Cr}\left(\mathrm{H}_{2} \mathrm{O}\right)_{6}\right]^{3+}$ and to chromium oxide-like compounds occluded in the channels, outside

(38) Pearce, J. R.; Sherwood, D. E.; Hall, M. B.; Lunsford, J. H. J. Phys. Chem. 1980, 84, 3215 .

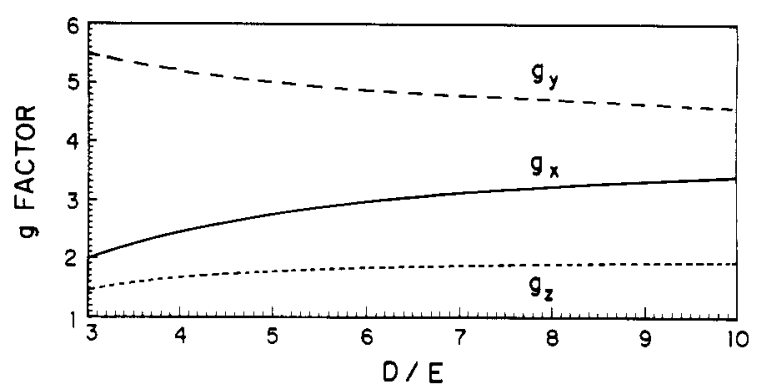

Figure 6. Theoretical prevision of effective $g$ factor in the $x, y$, and $z$ directions as a function of the ratio $D / E$.

the silicon framework. The EPR parameters for these different sites, shown in Table IV, are obtained by experimental fitting using the line width and the amplitude as adjustable parameters. The $\mathrm{Cr}$ (III) species in site $\mathrm{C}$ suffer no constraints and are expected to interact, the interaction between them being usually stronger as temperature decreases. In fact, the line centered at $g \cong 2.0$ shows a severe increase in line width as the temperature drops from 300 to $77 \mathrm{~K}$, clearly indicating smaller spin relaxation times. The line widths of the lines $A$ and $B$ are not significantly affected by changes in measurement temperature, indicating, as expected, a lower interaction between the $\mathrm{Cr}$ (III) species located in those sites.

Identification of the $C r(I I I)$ Species in Sites A and B. Assuming that the $\mathrm{Cr}$ (III) species, having an $L=0$ value associated to its orbital ground state, are located in cubic crystalline fields tetrahedrally distorted, the positions of the EPR spectrum lines can be calculated by solving the spin Hamiltonian in eq 2, where the parameters $D$ and $E$

$\mathscr{H}=g \beta H S+D\left[S_{z}{ }^{2}-(S / 3)(S+1)\right]+E\left(S_{x}{ }^{2}-S_{y}{ }^{2}\right)$

represent the axial and the rhombic distortions of the octahedron, respectively. The interaction of the $\mathrm{Cr}^{3+}$ ions, which have $\mathrm{d}^{3}$ electron configuration $(L=3, S=3 / 2)$, with the cubic crystalline field is strong and is the principal term determining the energy levels. Since the spin-orbit interaction and the crystalline field distortions act on the singlet orbital, the Zeeman term will split the two Kramer doublets and the energy levels will depend on the magnetic field and, consequently, on $D$ and $E . .^{39}$ Several transitions may occur between the levels for each direction of the magnetic field, and Figure 6 shows the expected $g$ value as a function of $D / E$ ratio for a particular direction of the magnetic field. For $D / E=6.5$ and $f=9.54 \mathrm{GHz}$ at room temperature, one finds a set of $g$ values in good agreement with those obtained for site A (see Table IV), confirming that $\mathrm{Cr}$ (III) is substituting Si(IV) in the silicalite skeleton. The assumptions made in the previous calculations do not provide any solution for site $B$, indicating that this is not a skeleton site but probably a highly distorted species trapped inside the channels. To distinguish both situations, the as-synthesized samples were ion-exchanged three times with aqueous $0.01 \mathrm{M} \mathrm{HCl}$, for $24 \mathrm{~h}$ at $80^{\circ} \mathrm{C}$. The EPR spectra of the ion-exchanged samples, shown in Figure 7, did not display site B peak anymore, showing that the $\mathrm{Cr}$ (III) species was washed away. Moreover the line corresponding to site $\mathrm{C}$ diminished considerably, making site A even more distinguishable. In line with this observation the weak band at ca. $680 \mathrm{~cm}^{-1}$ in the midIR spectrum is still present for the ion-exchanged material,

(39) Fuxi, G.; He, D.; Huiming, L. J. Non-Cryst. Solids 1982, 52, 135. 


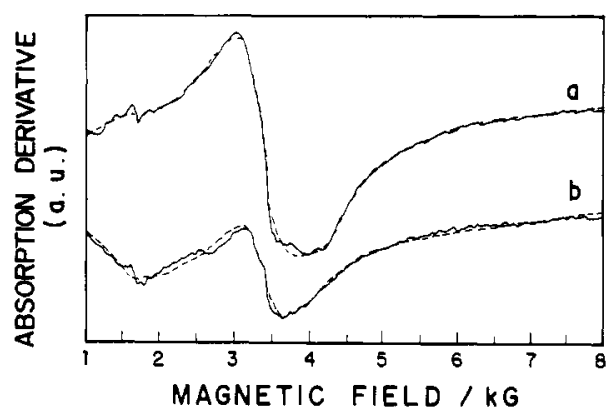

Figure 7. EPR spectra of chromium silicalite $\mathrm{Cr}-100$ (a) assynthesized, and (b) three times ion-exchanged with $\mathrm{HCl}$ solution. The dashed lines correspond to the best fit to the experimental curve.

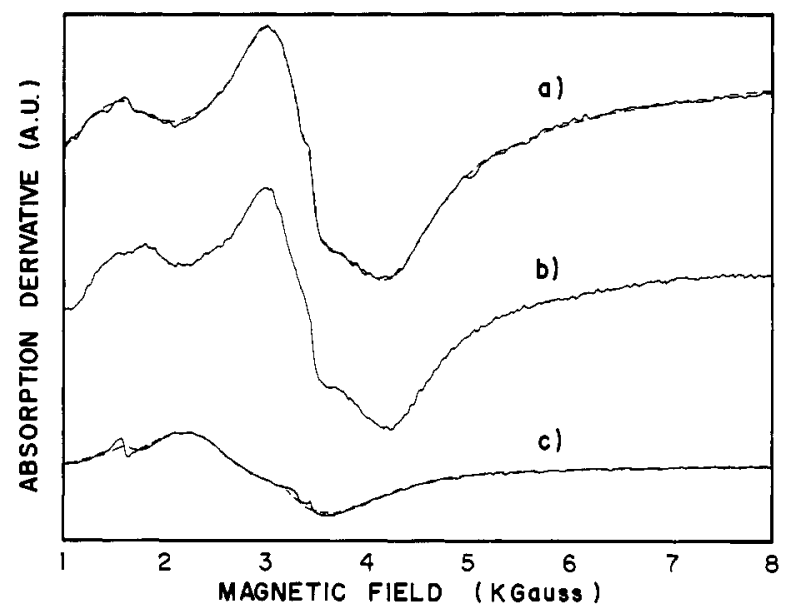

Figure 8. EPR spectra of the chromium silicalite, $\mathrm{Cr}-30$, (a) as-synthesized, (b) calcined at $693 \mathrm{~K}$ for $24 \mathrm{~h}$, and (c) calcined for $24 \mathrm{~h}$ at $843 \mathrm{~K}$.

supporting our previous assumption that this band is due to $(\mathrm{Si}-\mathrm{O}-\mathrm{Cr})_{n}$ group symmetric stretching.

Oxidation of Extraframework $\mathrm{Cr}(\mathrm{III})$ to $\mathrm{Cr}(\mathrm{VI})$. Calcination of a Cr-30 sample for $24 \mathrm{~h}$, at 693 and $843 \mathrm{~K}$, under oxygen flow, leads to incorporation of oxygen by the sample with oxidation of $\mathrm{Cr}$ (III) to $\mathrm{Cr}$ (VI) species. ${ }^{13}$ A comparison of the EPR spectra of a sample assynthesized and after calcination at $693 \mathrm{~K}$ (Figure 8) shows that they display essentially the same features except by a change in the relative intensities of the peaks within $g$ $=2.08$ and 1.66 related to sites $\mathrm{C}$ and $\mathrm{B}$, respectively. In spectrum $8 \mathrm{~b}$, the relative intensity $\mathrm{B} / \mathrm{C}$ is higher than for spectrum 8a, showing that $\mathrm{Cr}$ (III) species in site $\mathrm{C}$ (channels) were oxidized to EPR-silent $\mathrm{Cr}$ (VI) species. Calcination at $843 \mathrm{~K}$ leads to the complete oxidation of all sites and structure collapse. The effects of calcination in the IR and photoacoustic spectra were also examined. The IR spectra in Figure 9 show that the sample calcined at $693 \mathrm{~K}$ retained its MFI structure as determined by the $A^{550} / A^{450}$ optical density ratio equal to 0.77 for $9 \mathrm{a}$ and 0.74 for $9 \mathrm{~b}$. However, calcination at $843 \mathrm{~K}$ leads to the collapse of the crystal structure of the pentasil zeolite, as shown by the disappearance of the peaks at 550 and $450 \mathrm{~cm}^{-1}$ in Figure 9c. The photoacoustic spectra of the $\mathrm{Cr}-30$, assynthesized and calcined at $693 \mathrm{~K}$, are shown in Figure 10. The as-synthesized sample shows two bands centered at 440 and $640 \mathrm{~nm}$, assigned to the ${ }^{4} \mathrm{~A}_{2} \rightarrow{ }^{4} \mathrm{~T}_{1}(\mathrm{~F})$ and ${ }^{4} \mathrm{~A}_{2} \rightarrow$ ${ }^{4} \mathrm{~T}_{2}$ transitions, respectively, characteristic of $\mathrm{Cr}$ (III) species. After calcination at $693 \mathrm{~K}$ a strong band at 370 $\mathrm{nm}$ is observed, which is assigned to a charge-transfer absorption of $\mathrm{Cr}$ (VI). In Figure 10c it is possible to observe

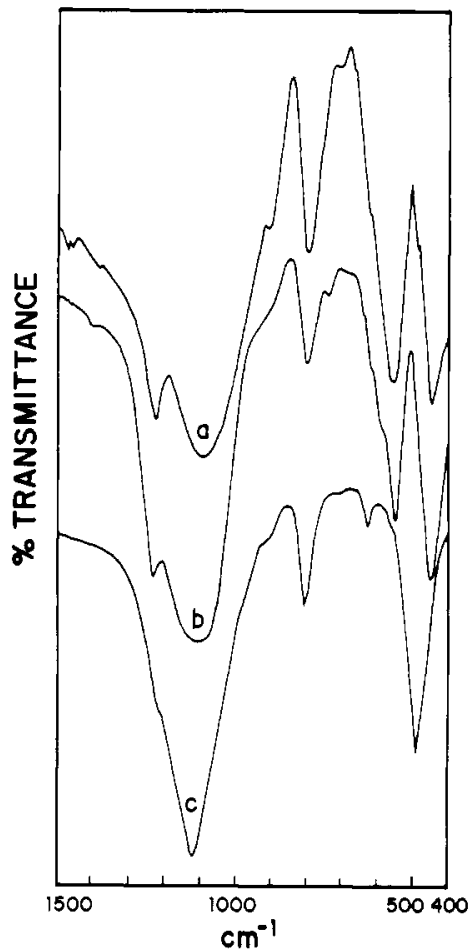

Figure 9. Mid-IR spectra showing the effect of calcination at increasing temperatures upon the zeolitic lattice integrity of sample Cr-30 (a) as-synthesized, (b) calcined for $24 \mathrm{~h}$ at $693 \mathrm{~K}$, and (c) calcined for $24 \mathrm{~h}$ at $843 \mathrm{~K}$.

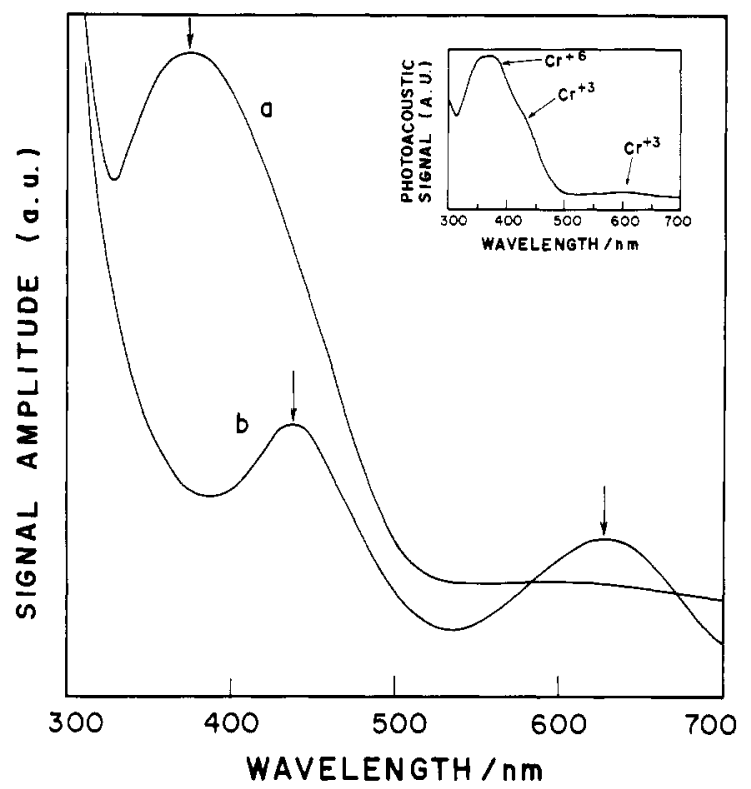

Figure 10. PA spectra of chromium silicalite $\mathrm{Cr}-30$, (a) calcined at $693 \mathrm{~K}$, (b) as-synthesized, and (inset) after extensive calcination at $693 \mathrm{~K}$ (on top). Arrows indicate the presence of two absorbing centers.

the very weak $\mathrm{Cr}$ (III) bands in the presence of $\mathrm{Cr}$ (VI), which provides a strong evidence that even after extensive calcination at $693 \mathrm{~K}$ some $\mathrm{Cr}$ (III) still remains in the chromium silicalite, very likely the ones in Si(IV) substitutional sites. It is interesting to note that $\mathrm{Fe}$ (III) species in the silicalite framework are stable to reduction, while $\mathrm{Fe}$ (III)-O species housed in the channels are reduced by $\mathrm{H}_{2}$ or CO to EPR-silent Fe(III) species. ${ }^{40}$ Therefore, redox cycles involving skeletal transition metal ions might not be as easy as one would expect based on solution chemistry.

Thermal Characterization. Apart from providing direct optical spectra, the photoacoustic technique can 


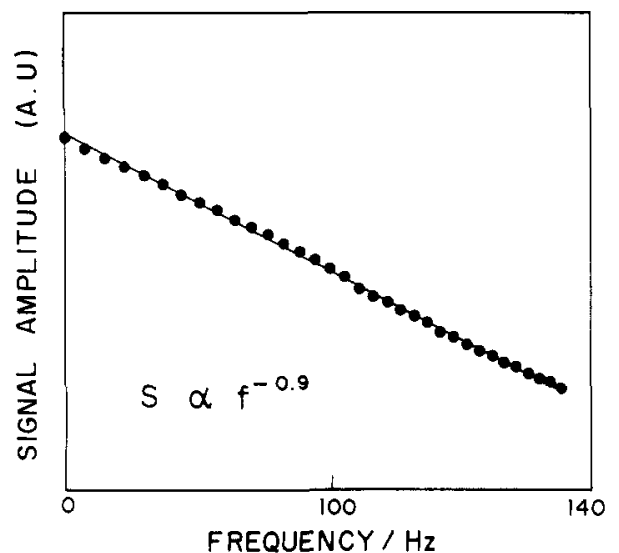

Figure 11. PA rear-signal amplitude for the $\mathrm{Cr}-30$ sample as a function of the modulation frequency, showing the $f^{-1}$ frequency dependence.

also be used in the characterization of thermal properties $^{41,42}$ as well as in the investigation of nonradiative relaxation processes. $15,43,44$

Thermal Diffusivity. Like the optical absorption, the thermal diffusivity, $\alpha$, is unique for each material and has been determined for a wide range of them, such as metals, minerals, and biological specimens. ${ }^{45}$ Furthermore, $\alpha$ is extremely dependent upon the effects of compositional and microstructural variables ${ }^{46}$ as well as processing conditions as in the case of polymers, ${ }^{47,48}$ ceramics, ${ }^{49}$ and glasses. ${ }^{49}$ The thermal diffusivities of the as-synthesized and calcined chromium silicalites were determined by photoacoustic spectroscopy, PA, using the signal data as a function of modulation frequency, $f$. By performing a rear-illumination signal amplitude measurement, we have determined that the thermal bending mechanism ${ }^{42,50}$ is the main reason for the detected PA signal in the modulation range of our experiments; i.e., the rear signal amplitude varies as $f^{-1}$. This is the expected modulation frequency dependence of the rear signal for a thermally thick sample when the thermoelastic bending dominates the PA signal. In Figure 11 the PA rear-signal amplitude is plotted versus the modulation frequency for a $\mathrm{Cr}-30$ calcined sample. A similar dependence is observed for the as-synthesized sample. The thermal diffusivity is obtained by fitting the front phase signal data to eq 3 ,

$$
\phi=\phi_{0}+\arctan [1 /(z-1)]
$$

where $z=a(f)^{1 / 2}$, with $a=\left(\pi l^{2} / \alpha\right)^{1 / 2}, l$ being the sample

(40) (a) Ball, W. J.; Dwyer, J.; Garforth, A. A.; Smith, W. J. Stud. Surf. Sci. Catal. 1986, 28, 137. (b) Kustov, L. M.; Kazansky, V. B.; Ratnasamy, P. Zeolites 1987, 7, 79. (c) Calis, G.; Frenken, P.; Boer, E.; Snolfs, A.; Hefni, M. A. Zeolites 1987, 7, 319. (d) Meagher, A.; Nair, V.; Szostak, R. Zeolites 1988, 8,3 .

(41) Adams, M. J.; Knikbright, G. F. Analyst 1977, 102, 678.

(42) Leite, N. F.; Cella, N.; Vargas, H.; Miranda, L. C. M. J. Appl. Phys. 1987, 61, 3023.

(43) Quimby, R. S.; Yen, W. M. J. Appl. Phys. 1980, 51, 1780.

(44) Pessog, O. Jr.; Cesar, C. L. Patel, N. A. Vargas, H. Chizoni, C. C.; Miranda, L. C. M. J. Appl. Phys. 1986, 59, 1316.

(45) Touloukian, Y.S.; Powell, R.W.;Ho,C. Y.; Nicolau, M. C. Thermal Properties of Matter; Plenum: New York, 1973; Vol. 10.

(46) Merté, B.; Korpium, P.; Lüsher, E.; Tilgner, R. J. Phys. (Paris) Colloq. 1983, 6, C463.

(47) Torres Filho, A.; Leite, N.F.; Miranda, L. C. M.; Cella, N.; Vargas, H. J. Appl. Phys. 1989, 66, 97.

(48) Ziegler, G.; Hansselman, A. P. H. J. Mater. Sci. 1981, 16, 495.

(49) Bento A. C.; Vargas, H.; Aguiar, M. M. F.; Miranda, L. C. M Phys. Chem. Glasses 1987, 28, 127. 2383.

(50) Rousset, G.; Lepoutre, F.; Bertrand, L. J. Appl. Phys. 1983, 54,

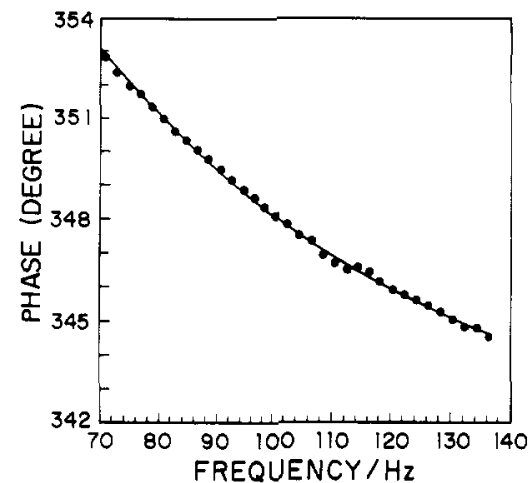

Figure 12. PA rear-signal phase dependence on the modulation frequency for the calcined $\mathrm{Cr}-30$. The solid line corresponds to the data fitting to eq 3 .

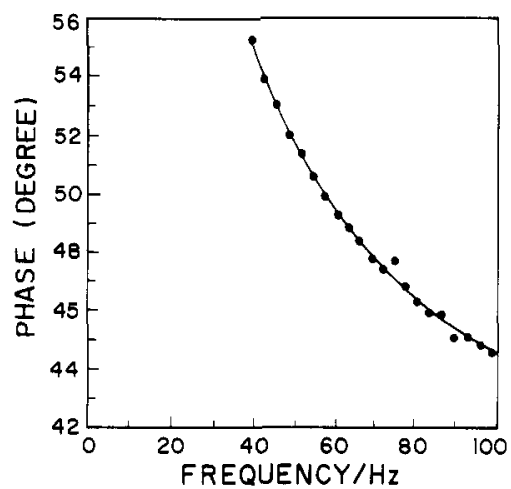

Figure 13. PA phase versus the modulation frequency at the 440-nm wavelength for the as-synthesized $\mathrm{Cr}-30$. The solid line corresponds to the data fitting to eq 4 .

thickness. Assuming $\phi_{0}$ and $a$ as adjustable parameters, the thermal diffusivity is obtained from the phase data fitting from the parameter $\alpha$. In Figure 12 the PA signal phase data for the calcined sample is shown as a function of the modulation frequency. The solid curve represents the fitting of the experimental phase data to the theoretical eq 3. The value of $\alpha$ obtained from the data fitting is $0.041 \pm 0.002 \mathrm{~cm}^{2} \mathrm{~s}^{-1}$. The same procedure was used for the as-synthesized sample, giving a value of $\alpha$ of $0.038 \pm$ $0.002 \mathrm{~cm}^{2} \mathrm{~s}^{-1}$.

Nonradiative Relaxation Processes. The PA signal also depends upon the light-into-heat conversion efficiency. This means that the PA signal is sensitive to the nonradiative deexcitation process which takes place after the absorption of the incident radiation. Information on the nonradiative deexcitation processes are obtained from the measurements of the PA phase angle as a function of the modulation frequency. For a thermally thick sample, the modulation frequency dependent part of the phase of the PA signal varies as shown in eq $4,{ }^{47}$ where $\tau$ is the

$$
\phi=-\pi / 2-\arctan (\omega \tau)-\arctan \left[\left(2 / \omega \tau_{\beta}\right)^{0.5}-1\right]^{-1}
$$

nonradiative relaxation time, $\tau_{\beta}=\left(\beta^{2} \alpha\right)^{-1}$ is the thermal diffusion time within the optical absorption depth $\beta^{-1}$, and $\omega$ is the modulation frequency. Equation 4 shows that the phase change of the PA signal with the modulation frequency of a given absorption band depends not only on its nonradiative relaxation time but also on the thermal diffusion time within the optical parameter depth. This modulation frequency has been used by several authors for studying the behavior of $\tau$ in collisional deactivation of vibrational excitation in gases and radiationless relax- 
Table V. Values of the Nonradiative Relaxation Time, $\tau$, the Characteristic Diffusion Time, $\tau_{\beta}$, and the Optical

Absorption Coefficient, $\beta$, for the Calcined and As-Synthesized Chromium Silicalite Cr-30

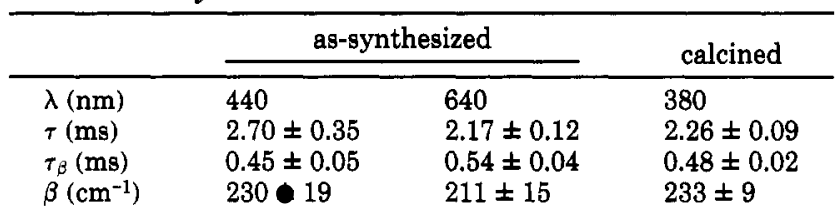

ation of dopant ions in crystals, ${ }^{43,51}$ glasses, ${ }^{52}$ and polymers. ${ }^{47}$ We carried out the fitting of the PA signal phase data of calcined and as-synthesized $\mathrm{Cr}-30$ samples using eq 4. The nonradiative relaxation times, $\tau$, and the optical absorption coefficients, $\beta$, of the 440- and $640-\mathrm{nm}$ crystal field band of the $\mathrm{Cr}$ (III) in the as-synthesized sample and of the 370-nm charge-transfer band of $\mathrm{Cr}$ (VI) species in the calcined sample were measured using PA phase data fitting to the corresponding expression contribution for optically transparent and thermally thick samples. Figure 13 shows a typical result of data fitting for the phase data obtained at $440 \mathrm{~nm}$, as a function of the modulation frequency $\omega$. The results for each absorption band together with the obtained values of $\beta$ and $\tau_{\beta}$ are summarized in Table V. Some conclusions might be drawn from the above results. First, the relaxation time, $\tau$, is not expected for the level initially excited but rather for the average lifetime of a variety of states before energy is lost as heat. Thus, we may have a non-unique relaxation pathway consisting of several successive steps, and the measured lifetime is an average lifetime for heat production. Furthermore, for powdered samples, as is the case of the present work, $\tau$ also contains a contribution from the heat exchange time between the powder particles and the transducing gas of the PA cell. This heat exchange time depends not only on the shape of the particles but also on their size. The fact that the average of $\tau$ for $\mathrm{Cr}$ (III) in the as-synthesized sample is equal within the experimental error to the one obtained for the calcined sample shows that the mechanism of relaxation for $\mathrm{Cr}$ (VI) is not very different to the one used for $\mathrm{Cr}$ (III) to transfer the heat generated upon absorption of radiation.

(51) Murphy, J. C.; Aamordt, L. C. J. Appl. Phys. 1977, 48, 3502.

(52) Lima, G. A. R.; Baesso, M. L.; Arguello, Z. P.; Silva, E. C.; Vargas, H.; Miranda, L. C. M. Phys. Rev. B 1987, 36, 9812.

\section{Conclusions}

The combination of several physical techniques leads to the characterization of a chromium containing silicalite material prepared hydrothermally from a neutral fluoride suspension. The main conclusions are summarized below as follows:

PXRD-calculated unit cell volumes have shown that co-incorporation of small concentrations of chromium with aluminum, in a ZSM-5-type structure, still yields expanded unit cells.

The mid-IR spectra show a very week band around 680 $\mathrm{cm}^{-1}$, whose intensity is not affected by ionic exchange or calcination, assigned to ( $\mathrm{Si}-\mathrm{O}-\mathrm{Cr}$ ) groups symmetrical stretching vibrations. Shoulders at the lower wavenumber side of the band around $1100 \mathrm{~cm}^{-1}$, previously assigned to $\nu_{\mathrm{a}}-(\mathrm{Si}-\mathrm{O}-\mathrm{M})_{n}-{ }^{35}$ disappear after calcination and might be due to $\mathrm{Si}-\mathrm{OH}$ or $\mathrm{Si}-\mathrm{F}$ vibrations. ${ }^{36}$

EPR measurements have shown that there are two distorted $\mathrm{Cr}$ (III) species, $\mathrm{A}$ and $\mathrm{B}$, in the chromium silicalite, none of which can be oxidized after $24 \mathrm{~h}$, at 693 $\mathrm{K}$ under $\mathrm{O}_{2}$ flow. One of them is ion exchanged in aqueous $\mathrm{HCl}$ solution. A third $\mathrm{Cr}$ (III) site, $\mathrm{C}$, is spherically symmetric and is extensively oxidized to $\mathrm{Cr}$ (VI). This led us to propose that site $A$ is the actual $\mathrm{Si}$ (IV) substitutional site in the silicalite framework, while site B is only a highly distorted channel-located $\mathrm{Cr}$ (III) species, probably cationic, whose nature is yet unknown. Site $\mathrm{C}$ contains chargebalancing and oxide-like $\mathrm{Cr}$ (III) species.

The optical absorption spectra measured by photoacoustic spectroscopy show the typical bands for $\mathrm{Cr}$ (III) at $440 \mathrm{~nm}\left({ }^{4} \mathrm{~A}_{2} \rightarrow{ }^{4} \mathrm{~T}_{1}(\mathrm{~F})\right)$ and in $640 \mathrm{~nm}\left({ }^{4} \mathrm{~A}_{2} \rightarrow{ }^{4} \mathrm{~T}_{2}\right)$ and the charge-transfer band at $370 \mathrm{~nm}$ of $\mathrm{Cr}(\mathrm{VI})$ species and revealed the presence of unoxidized $\mathrm{Cr}$ (III) framework sites even after extensive oxidation.

By using special techniques and equipment, the photoacoustic spectroscopy allowed for the determination of the thermal diffusivity, $\alpha$, of as-synthesized $(0.041 \pm 0.002$ $\left.\mathrm{cm}^{2} \mathrm{~s}^{-1}\right)$ and calcined $\left(0.038 \pm 0.002 \mathrm{~cm}^{2} \mathrm{~s}^{-1}\right)$ chromium silicalite samples, as well as their nonradiative relaxation times, $\tau$ and $\tau_{\beta}$, and absorption coefficient for each band.

Acknowledgment. Financial support from FAPESP, CAPES, and CNPq is gratefully acknowledged. We are indebted to Prof. J. S. Barone for the chemical analysis. 